\title{
Ideologia de Jehan de Murs
}

\section{Lorenzo Mammì}

Dos primeiros sinais de rítmica modal às complexas combinações do moteto isorrítmico transcorre pouco mais de um século. Nesse período relativamente breve nasce e amadurece a idéia de um sistema completo e perfeitamente definido de durações, independente do texto, da liturgia ou da dança - o tempo musical como o entendemos ainda hoje, elemento da composição e função da sua forma, valor estético.

O tratado Notitia Artis Musicae de Jehan de Murs, que será examinado aqui, já pertence à fase culminante desse processo, à Ars Nova. Procurarei lê-lo em seus aspectos ideológicos, mais do que técnicos, tentando decifrar, por meio dele, as concepções do tempo, da arte e da composição musical que fundamentaram a revolução arsnovista. ${ }^{1}$

Antes de enfrentar o texto, porém, será necessário fixar alguns pontos de referência, que permitam situá-lo na cultura e na sociedade do final da Idade Média.

\section{O tempo cotidiano.}

Em Mons, na França, em meados do século XII, ocorre um duelo judiciário. Um dos contendedores não se apresenta e tem-se a impressão, a uma certa altura, que o tempo fixado para o desafio tenha se esgotado. Consultam-se juizes, depois os monges de um convento próximo que, devido às obrigações da liturgia, medem o tempo e o escandem com os sinos. Decide-se enfim que a hora nona, último termo do duelo, já passou. A anedota é contada por Marc Bloch, para exemplificar a indeterminação temporal em que vivia o homem da Idade Média. ${ }^{2}$

Dando prosseguimento às pesquisas de Bloch, Jacques Le Goff dedicou dois ensaios à transformação da sensibilidade cronológica da sociedade urbana dos séculos XIII e XIV. ${ }^{3}$ A nova economia, baseada no comércio e numa produção de tipo préindustrial, necessitava de um tempo mais definido. Os conflitos sobre os horários de trabalho levaram, no século XIV, à instalação de um "sino do trabalho" e, logo depois, de um relógio da cidade, nos principais centros da França e da Itália do Norte. Em 1370, Charles V ordena que todos os sinos de Paris sejam regulados a partir do relógio do palácio, unificando assim o tempo urbano de modo definitivo.

Esses são, porém, apenas os últimos assentamentos de uma evolução que remonta ao século anterior e que marca a passagem gradativa de um tempo natural, decalcado dos movimentos do sol, a um tempo abstrato, escandido pelo relógio mecânico. Tomás de Aquino já notava:

As horas do dia se definem de duas maneiras: podem ser iguais ou desiguais. Iguais são aquelas calculadas segundo o movimento do sol no equinócio; dessa forma, nem todos os dias têm doze horas, mas apenas o dia do equinócio; os outros têm mais ou menos horas. As horas desiguais, ao contrário, são calculadas segundo os movimentos do zodíaco; por causa da obliqüidade da orbita, as casas do zodíaco não transcorrem todas na mesma velocidade, a não ser no equinócio; e dessas horas desiguais cada dia tem doze, porque a cada dia transcorrem seis signos de dia e seis de noite; mas no verão são mais lentos do que no inverno; e a cada signo calculam-se duas horas. 
Mais ou menos nos mesmos termos, anos depois, Dante explicará a que estão no Convivio. ${ }^{4}$

Existiam, portanto, já antes que os conflitos de trabalho obrigassem a uma sistemática definitiva do tempo urbano, dois tipos de medida. Um, aderente à vida dos campos, não tinha outra referência além do ciclo cotidiano do sol; o outro se adaptava à economia mercantil, à necessidade de calcular o horário dos operários, o tempo de transporte da mercadoria, etc. Sua unidade era uma hora de duração fixa, produto da divisão do dia em 24 partes iguais.

É natural que a classe intelectual compartilhasse com o mercador a mesma sensibilidade a respeito do tempo, não só porque aquela classe também se concentrava nos espaços urbanos, mas porque conduzia, tanto quanto os mercadores, uma vida desligada dos ciclos naturais. Alexander Murray sublinhou a crônica falta de tempo desses literatos, que confundiam o dia com a noite, debruçados sobre os livros ou ocupados em serviços políticos. ${ }^{5} \mathrm{O}$ orgulho de uma consciência exata do tempo transparece na imaginativa etimologia do gramático Johannes de Garlandia, já no começo do século XIII:

As campanae (sinos) são assim chamadas por via dos camponeses que habitam os campos e que não sabem julgar o tempo a não ser pelas campanae ${ }^{6}$ (grifo meu).

\section{Música e escola.}

O período em que se estabelecem as regras e os signos das duraçóes musicais coincide portanto com aquele em que toma forma o tempo abstrato do relógio. Mas que uma transformação do tempo cotidiano tivesse de produzir necessariamente uma reformulação do tempo musical parece óbvio apenas a nós, acostumados a definir a música como "arte do tempo". Nada indica que o tempo fosse uma função específica da música, antes do fim do século XII. É preciso, pois, supor que se tenha verificado, num ponto determinado da história, uma conexão entre duas areas antes distintas do pensamento; uma cultura musical que se ocupava, até então, apenas de intervalos melódicos e harmônicos, e uma organização cronológica sempre mais pormenorizada e exata.

Um elemento pode ser logo evocado: a música pertencia, na cultura medieval, às artes liberais, formando, junto com a aritmética, a astronomia e a geometria, o grupo das ciências matemáticas, o Quadrivium. Quem ensinava astronomia, nas escolas catedrais ou monásticas, ensinava também música; é natural que houvesse trocas de conceitos e de métodos entre uma disciplina e a outra.

Mas, infelizmente, as coisas não são tão simples. Existiu por longo tempo, na didática da Idade Média, uma cisão profunda entre música prática e música como arte liberal. Nas catedrais, o ensino e a biblioteca eram responsabilidade do scolasticus, papel de alto prestígio, ou até do próprio bispo, enquanto o treinamento do coro e os livros de música eram confiados a um decano. Guido tinha exercido essa função por muitos anos em Arezzo, antes de escrever, em um tom talvez polêmico, que o De musica de Boécio "não serve aos cantores, mas apenas aos filósofos". ${ }^{7}$ De fato, na maioria dos casos, as noções de música transmitidas nas escolas limitavam-se a poucas fórmulas extraídas dos compêndios da latinidade tardia (Boécio, Cassiodoro, Isidoro de Sevilha), já desligados da realidade musical. 
Giulio Cattin ${ }^{8}$ assinala que, nos cursos universitários de quatro Magistri artium do século XIII, que se conservaram em resumos, nenhuma alusão é feita à polifonia, enquanto muito espaço é dado a definições e distinções como aquela boeciana entre música mundana, humana e instrumental. Dado surpreendente, se se considera que esses cursos foram ministrados enquanto a Ars Antiqua estava em pleno desenvolvimento, e que dois desses magistri são, em outros campos, protagonistas da renascença científica da Idade Gótica: Michael Scott e Roger Bacon.

O que sabemos sobre a primeira polifonia não provém dos magistri, mas de autores que se ocuparam concretamente da organização do canto nos monastérios e nas igrejas, como Guido de Arezzo. Por outro lado, é preciso dizer que a cultura desses músicos práticos incluía normalmente um certo conhecimento do que hoje chamaríamos ciências aplicadas: Guido escreveu, além dos textos musicais, um tratado sobre o ábaco; de Hermannus Contractus existem estudos relativos à música, ao ábaco, ao astrolábio e a um jogo matemático chamado "Rithmomachid"; além disso, na biografia redigida por um discípulo, o monge alemão é lembrado como construtor de instrumentos musicais e de relogios; Frutolf de Michelsberg, que retomou as teorias de Guido e redigiu um tonário, é o autor provável de uma outra Rithmomachia. ${ }^{9}$

Sem dúvida, seria um erro separar radicalmente esses conhecimentos técnicos da cultura liberal. Freqüentes eram as intersecções, por exemplo, nas compilações enciclopédicas a que se dedicavam filósofos e teólogos; mais tarde, os contatos tornaram-se sistemáticos graças aos tratados árabes traduzidos na Espanha: cinco livros sobre relógios (para limitarmo-nos à questão da mensuração do tempo) integram os Libros del Saber de Alfonso X. Mais ou menos na mesma época, Hugues de St. Victor propôs em Paris um novo modelo de estudos que incluía, além das sete artes liberais, sete artes mecânicas: têxtil, militar, naval, agrícola, venatória, médica, teatral (arquitetônica). 10

É, porém, apenas no século XIII, graças à nova organização do saber nas universidades, que o processo de unificação entre as duas culturas se acelera. Só nas universidades a cultura medieval liberta-se de uma dependência direta da Igreja, embora a Igreja continue sendo a referência principal, e estabelece relações com todos os aspectos da vida urbana; é lá que os intelectuais constituem-se como uma classe social distinta, com direitos e privilégios corporativos; finalmente, é lá que, em competição com a Faculdade de Teologia, os magistri artium assumem posturas sempre mais orgulhosamente racionalistas, em detrimento da autoridade e do dogma. Não é por acaso, assinala Le Goff, que os pregadores da época associavam mercadores e mestres sob a mesma acusação de impiedade. Aqueles vendiam o tempo, através da agiotagem e da usura, estes vendiam o saber - duas coisas que pertenciam a Deus e não aos homens. 11

\section{Escolástica e arte nova.}

Que a Ars Nova, na época do seu surgimento, gozasse de um alto prestígio acadêmico já se deduz pelos textos musicados, predominantemente em latim, enquanto a produção não litúrgica que a antecede e a segue imediatamente é, em sua maioria, em vulgar. O próprio termo Ars Nova, em oposição a Ars Antiqua ou Ars Vetus, denuncia uma origem universitária - é um decalque da oposição Logica Vetus/Logica Nova que, no programa de estudos da Faculdade de Artes, distinguia as 
partes do Organon aristotélico já traduzidas por Boécio, e conhecidas desde a Antiguidade, daquelas traduzidas há pouco do árabe ou do grego e admitidas pela Igreja como matéria de ensino apenas em $1255 .^{12}$

Sabe-se que Philippe de Vitry, e mais ainda Jehan de Murs, ambos magistri artium na Sorbonne, se ocuparam de questões científicas. A Philippe são dedicados o Opus quadripartitum numerorum de Murs e o Algorismus proportionum, de um cientista do porte de Nicola de Oresme; o De numeris harmonicis de Leão Gersonide nasceu de um problema posto por Philippes, provavelmente relacionado com a definição do tempo musical. A Jehan de Murs devem-se, além do grande tratado dedicado a Vitry, diversos estudos de astronomia e de astrologia, que desembocaram numa organização do tempo em frações sexagesimais: dias de 24 horas, horas de 1080 puncta, de 10 momenta. ${ }^{13}$

É claro que a cultura científica de Jehan de Murs é muito mais complexa e rica do que a de Guido ou de Hermannus Contractus. Mas aqui também não se perde a relação com a prática. Do Opus quadripartitum, as três primeiras partes são dedicadas à matemática pura, a última às suas aplicaçóes e, no poema dedicatório que encerra o livro, o autor comenta: "Esta obra é dividida em quatro partes. A primeira fornece as raízes, a segunda dá a linfa, a terceira produz as flores e a última saboreia os frutos".

Relações estreitas entre pesquisa científica e teoria musical podem ser (e foram) detectadas nos autores da Ars Nova. Aqui parece mais útil deter-se sobre um elemento metodológico e gnosiologico, próprio da cultura escolástica, que com certe$\mathrm{za}$ facilitou essas correspondências e que constitui um fato novo em relação aos séculos anteriores.

Erwin Panofsky ${ }^{14}$ estudou as ligações existentes entre arquitetura gótica e pensamento escolástico, chegando a distinguir dois modus operandi comuns aos arquitetos e aos filósofos: a manifestatio, isto é, a tendência a tornar evidente por si a estrutura lógica do discurso, independentemente do conteúdo específico, por meio de articulações detalhadas e repetidas simetrias; a disputatio, isto é, a organização formal baseada sobre uma série de oposições, de prós e contras, nos moldes das discussóes públicas que a Universidade promovia periodicamente.

Não é difícil reconhecer ambos os procedimentos na prática musical contemporânea. A estrutura isorrítmica do moteto da Ars Nova, sua divisão em colores e taleae, é um tipo de manifestatio, análoga à organização em livros, capítulos, subcapítulos cuidadosamente simétricos nas Summae universitárias. Por outro lado, a sobreposição de melodias com textos contrastantes, mas relacionados a um tema posto pelo tenor (como em Ocanenda - Rex que metrorum - Rex Regum de Philippe de Vitry), pode se assemelhar a uma disputatio. Mas nas páginas de Jehan de Murs está presente ainda um outro elemento que diz respeito, mais do que à metodologia, à teoria do conhecimento: a abstractio.

A questão era aquela, secular, dos universais. Discutia-se se os gêneros e as espécies (por exemplo, a Humanidade) eram realidades extramentais ou apenas conceitos. Os mestres mais antigos se inclinavam pela primeira hipótese: os universais (genéricos e específicos) eram identificados com as Idéias platônicas, que existem de fato em Deus ou com Deus, e das quais as criaturas particulares eram meras cópias imperfeitas ("reflexos da luz nas plumas de um pavão", escreveu Scotus Eriuge- 
$\mathrm{na}^{15}$ ); mas havia também quem, como Heiric d'Auxerre e mais tarde Roscelin, afirmasse que gêneros e espécies eram apenas expressões (flatus voci) úteis para reunir indivíduos símiles em grupos.

A solução predominante na Escolástica madura foi esboçada por Abelardo e aperfeiçoada aos poucos até Santo Tomás, seguindo uma via intermediária: os universais não têm realidade fora dos indivíduos, mas não são apenas conceitos. Todo indivíduo é composto de elementos acidentais, que o diferenciam dos indivíduos da mesma espécie, e de uma essência, que é universal. Em outras palavras, a Humanidade não existe para além dos homens singulares, mas todo homem, liberado dos elementos acidentais, ć uma Humanidade. O conhecimento se identifica portanto com um processo de sucessivas abstrações a partir dos dados sensíveis, até as verdades mais gerais e últimas. Em seu orgulhoso intelectualismo, Tomás afirmava que o universo inteiro, e até as naturezas angelicais, podiam ser compreendidas por essa via, sem recorrer à iluminação divina - apenas a essência de Deus permanecia inalcançável. ${ }^{16}$

A questão é de importância extrema para o desenvolvimento não só de músicas, mas de todas as linguagens artísticas. Se apenas os universais têm valor de ente, e os indivíduos são meras cópias, o conhecimento sensivel é rebaixado a mera ilusão; se, ao contrário, os universais não passam de termos arbitrários, criados para organizar a realidade, não é mais possível algum contato entre experiência sensível e realidade transcendente. Só quando a cada indivíduo se reconhece uma essência, passível de ser alcançada por meio de um processo intelectual, é que se cria aquela união entre experiência singular e valor universal que estamos acostumados a atribuir à obra de arte. Delineia-se assim um modelo de atividade artística que consiste em extrair princípios abstratos de experiência sensível, para depois construir formas em que esses princípios transpareçam com a maior proporção, perfeição e clareza possíveis.

Um dos artistas que Panofsky cita entre os mais próximos ao pensamento escolástico, o arquiteto Villard de Honnecourt, deixou-nos um caderno de desenhos em que formas humanas e animais são sobrepostas a figuras geométricas. A finalidade não é tanto garantir as proporções do desenho quanto reduzir a figura a esquemạ. Ao lado de um leão estilizado, Villard anota: "Et savez bien qu'il fu contrefait al vif" (E saibam que foi copiado ao vivo) - certamente não para se vangloriar da semelhança do desenho com o modelo; talvez para sublinhar a habilidade com que obtinha, de um leão verdadeiro, a forma essencial do leão. ${ }^{17}$ Analogamente, no Paraíso de Dante, as luzes angelicais se dispõem em forma de $M$ (inicial de Monarquia) para então desenhar, com pequenos ajustes cuidadosamente descritos, a imagem de uma águia (símbolo do Império). Sugere-se assim, pela estilização do símbolo, uma relação profunda com a idéia simbolizada. ${ }^{18}$

De que maneira essa relação figura/esquema pode se dar na música? Jehan de Murs, a meu ver, não só responde a essa questão em seu tratado como oferece um caminho para superá-la, colocando-se na passagem entre a estética medieval e a renascentista.

\section{Tempo, ciência e arte no Notitia Artis Musicae.}

Não se deve esperar, do Notitia, novidades técnicas comparáveis àquelas do Ars Nova de Philippe de Vitry. Jehan de Murs escolhe uma postura prudente, e odeclara: 
Na nossa arte existem coisas escondidas que, se fossem trazidas à luz, obrigariam a calar-se imediatamente aqueles que discutem sem parar sobre certos assuntos. Por isso, por amor daqueles mais do que da verdade, quisemos aceitar plenamente alguns princípios que hoje são muito discutidos. Não se levante, pois, um acusador hostil, se forçamos as formas musicais a dizer coisas inauditas, salvando as aparências e respeitando os limites postos pelos antigos. (II, VII, 3)

Se o Notitia é em grande parte tradicional quanto às regras musicais, dedica porém, em comparação com o tratado de Vitry, muito mais espaço aos problemas estéticos e metodológicos. Desde o prólogo, a questão da abstractio é posta com clareza:

Aristóteles, príncipe dos filósofos, diz no proêmio da sua Metafisica: a possibilidade de ser ensinada é caráter próprio da ciência. Mas em toda arte os teóricos podem ensinar, os práticos não. (...) Julgamos que entender e conhecer uma arte depende mais da teoria do que da prática. Logo, estimamos os teóricos mais sapientes do que os práticos e a arte mais ciência do que experiência, porque os teóricos podem ensiná-la, os práticos não. Tratando porém a arte de universais, e a experiência de singularidades, a arte pressupõe a experiência. É necessário, portanto, em qualquer arte, dominar antes de tudo a parte teórica, depois a prática correspondente, de modo que o que foi apreendido a nivel de universais possa ser aplicado às singularidades. Mas, dependendo a arte da experiência, é preciso que o artista se aprimore antes no aspecto prático.

As duas últimas frases desse trecho parecem conter uma contradição. Afinal, é a prática ou a teoria que ocupa o primeiro lugar? Na verdade, Jehan de Murs está pensando aqui num movimento duplo: dos dados empíricos extraem-se os princípios universais que, por sua vez, serão fundamento da prática artística, isto é, da construçăo de outros objetos de experiência. O processo se delineia nitidamente no capítulo III do primeiro livro, dedicado à "invenção da música":

Pitágoras não queria confiar no juízo do ouvido quanto às consonâncias, porque não é raro que os sentidos errem, no que não pertence a eles (e o ouvido julga o som, mas entende pouquíssimo de proporções). Estava portanto em angústia, não sabendo como alcançar um conhecimento racional das consonâncias, quando, passando perto de uma oficina de serralheiros, ouviu martelos que, batendo em alternância, produziam uma maravilhosa harmonia. Surpreso, dirigiu-se aos serralheiros e, duvidando que a consonância dependesse das diversas forças dos homens, pediu para que trocassem de martelos; ouviu a mesma música e entăo compreendeu que essa harmonia provinha de uma certa relação entre as naturezas dos martelos.

Os martelos eram cinco, mas o quinto foi descartado, porque dissonante. Sobraram portanto quatro, cujos pesos resultaram em proporção 1:2, 2:3, 3:4 e 8:9. Essa proporção foi verificada pacientemente em instrumentos de cordas e de sopro, em órgãos pneumáticos e hidráulicos. Reunindo essas experiências na memória, Pitágoras alcançou um princípio universal, que colocou na base da arte e ciência musical." (I, iii, 2-6)

É so pelo dado físico, pelo experimento conduzido com paciência, que o princípio universal pode ser obtido. Essa precedência do elemento concreto em relação à forma abstrata era, na verdade, evidente desde o primeiro capítulo, sobre a "geração do som".

A música trata do som em relação aos números, e vice-versa; é necessário, portanto, que 0 músico estude tanto os números quanto os sons. Mas, para que algo possa ser objeto de cálculos, é preciso que ele exista. O som, portanto, deve ser produzido antes de ser traduzido em números. (I, i, 2-3) 
Observação aparentemente anódina, que permite, porém, organizar a passagem do dado sensível a conceito abstrato através de uma seqüência contínua e perfeitamente articulada. O som é gerado pela ação de um percussor sobre um corpo percutido. Esse primeiro movimento produz um movimento secundário, a vibração do ar. Aqui se verifica a primeira defasagem entre experiência sensível e conhecimento racional: a vibração, embora pareça gerar um som contínuo, é na realidade constituída de uma série de pulsões sucessivas "assim como um ponto de cor no vértice de um corpo em movimento rotatório parece uma linha circular, embora não passe de um ponto". (I, i, 8) O número e a velocidade das pulsões determinam a altura do som - é aqui que entram em jogo as proporções numéricas.

O movimento está, assim, na origem do som, e à mensuração do movimento se reduzem, no final das contas, as proporções musicais: "não há percussão sem movimento, logo, sem movimento não há som". (I, i, 5) E o movimento é também o nexo em volta do qual se articulam as duas partes do tratado: o primeiro livro é dedicado à música teórica, isto é, a questões relativas à definição proporcional dos intervalos, que sempre foi assunto dos magistri; o segundo livro, muito mais extenso, trata, sob o título de música prática, das duraçōes musicais e de sua representaçāo gráfica. Assim abre-se o segundo livro, com um capítulo intitulado, significativamente, "A noçăo de tempo":

Nos capítulos anteriores tratamos brevemente da música tébrica: agora deveremos nos ater mais à parte da música prática que é mensurável, porque sobre esse ponto diversos músicos entendem diversamente.

Como foi mostrado no primeiro livro, o som é gerado por um movimento e pertence ao gênero das sucessócs. Isto é, existe enquanto é gerado mas, uma vez gerado, não existe mais. Não há sucessão sem movimento. Portanto, é necessário que o som seja medido no tempo. Porque o tempo é a medida do movimento."

A definição aristotélica do tempo, sobre a qual concordava toda a cultura da época, assume aqui uma função estratégica. A predileção da Ars Antiqua pelos ritmos ternários era, de fato, puramente formal, dedutiva, sem referência aos fenômenos concretos. Jehan de Murs enumera suas razões:

Em Deus, que é perfeitíssimo, a substância é uma, as pessoas três. Ele é uma unidade ternária e uma tríade unitária. Logo, a relação mais harmônica é a de um com três. $\mathrm{Na}$ inteligência que procede de Deus, essência, existência e união das duas formam um número ternário. No primeiro céu dos corpos: motor, móvel e tempo. Nas estrelas e no sol: calor, raio esplendor; nos elementos: atividade, passividade, matéria; nos indivíduos: geração, corrupção, sujeito; em todo tempo finito: começo, meio, fim; em toda doença curável: crescimento, êxtase, declínio.

Três são as operações do intelecto: três os termos do silogismo; três as figuras da argumentação; três os princípios intrínsecos das coisas naturais; três as potências do ente na sua integridade; três as diferenças correlativas de lugar; três as dimensões do Universo. (II, ii, 2-0)

Nessa rígida hierarquia, que parte de Deus para descer gradualmente até os indivíduos, o tempo não é tanto medida de movimentos reais, concretos, quanto expressão dum movimento presumido, invisível, que a astronomia medieval imaginava num céu remotíssimo, além das estrelas fixas. Sua divisão em começo, meio e fim é fruto de um raciocínio analogico e não da observação dos fenômenos físicos. É justa- 
mente por analogia que a forma ternária era considerada perfeita em campo musical. Mas, anota Jehan de Murs, "alguns modernos, discordando, julgaram ter descoberto o contrário disso; a opinião deles será explicada mais claramente em seguida". (II, i, 8)

E uma promessa que o tratado não cumpre totalmente. As questões mais controvertidas são enfrentadas de modo oblíquo, por alusões fragmentárias - o suficiente, porém, para detectar uma concepção do tempo que não pode ser reduzida aos esquemas tradicionais. Sobre a notação, por exemplo:

Tudo o que uma voz contínua, plena e regular pode cantar, o músico competente deve pode-lo representar com signos correspondentes. As figuras são signos dos sons, porque não é a arte que regula a natureza nem as notas o canto, mas o contrário. De fato, podemos cantar sem notas. Às vezes, é perfeitamente natural e adequado cantar oito ou cinco semibreves com uma única emissão de voz; logo, elas devem ser representadas com uma única figura. (II, $\mathrm{x}, 6$ )

Mais clara ainda é a "nona conclusão" do tratado:

Que o tempo possa ser dividido em um número qualquer de partes iguais, é evidente pelo seguinte: todo ente contínuo pode ser dividido em sua extensão em qualquer número de partes, em duas, três, quatro etc.; o tempo pertence ao gênero dos contínuos; logo, pode ser dividido em um número qualquer de partes iguais.

Cantem-se, portanto, $2,3,4,5,6,7,8,9$ semibreves sobre a mesma nota (não é possível, de fato, cantar bem além desse limite). Cante-se dividindo por três ou por duas partes iguais. Dois mais três são cinco, duas vezes dois quatro, dois por três seis, quatro mais três sete, dois por quatro oito, três por três nove. Todas essas divisões são equivalentes, logo, podemos cantar igualmente com todas elas. Louvável e experiente é o músico que sabe fazer contraponto sobre um mesmo valor, dividindo ora por duas, ora por três ou mais partes. (II, xiii, 2-7)

Ao tempo metafísico da teoria tradicional, Jehan de Murs opõe os tempos que são realmente cantáveis. A divisão em valores ternários ou binários não diz respeito à natureza do tempo, que é contínuo, mas à maneira com que o organizamos. Os limites naturais da voz e a natureza das combinações numéricas compõem o horizonte no qual é possível uma plena liberdade de escolha.

Vale a pena resumir brevemente as articulações principais do Notitia Artis Musicae. No primeiro livro, isto é, na música teórica, as proporções matemáticas dizem respeito a uma verdade mais profunda do que a aparência sensível. Por meio delas, o músico-cientista mede, além da ilusão de continuidade, as vibrações sucessivas dos corpos, as freqüências. No segundo livro, na música prática, o músico-artista parte do dado sensível, isto é, do som como contínuo, e o divide em durações distintas e sucessivas. Os ritmos musicais serão, pois, um revelador da natureza do som, que é série de movimentos que, "uma vez gerados, já não existem mais". Como a Natureza constrói, por uma pulsação regular, um tempo contínuo, assim o artista extrai da continuidade um tempo regularmente escandido. Essa escanção não existe no som, mas na nossa mente - diz porem algo de essencial sobre a natureza do som.

Até aqui, o pensamento de Jehan de Murs poderia ser remetido ao esquema indutivo/dedutivo que é próprio da metodologia aristotélica e escolástica. Mas, e aqui reside a principal novidade, o Notitia admite também o percurso inverso: o tempo musical não é necessariamente um valor a priori, uma estrutura lógica eterna; 
pode ser, ao contrário, um produto da própria prática musical, a totalidade dos tempos cantáveis. Ao lado do contínuo e dos átimos em rápida sucessão - extremos que indicam o mesmo objeto, a corrente de movimentos perfeitamente articulados que constitui o universo - Jehan de Murs descobre um outro tempo, aquele dos gestos e dos feitos humanos, que depende de vontades e de escolhas, um tempo histórico. Assim, de fato, encerra-se o tratado:

Talvez aconteça a nós, por algum tempo, o que aconteceu aos antigos, que acharam ter encontrado a última fronteira da música. Nunca, porém, diga-se que chegamos a um limite último e imutável. As opiniões e as revoluçóes científicas correm em círculo, até agradar à suma vontade dAquele que sem necessidade criou cada coisa desse mundo e voluntariamente a destruirá. (II, xiv, 5-6)

Não é possível deixar de lembrar, lendo esse trecho, o que o historiador da filosofia Eugenio Garin escreveu sobre a Renascença, sobre a distinção entre cultura humanística e gótica:

Plantas, pedras, bichos, estrelas entram no discurso do homem, e o homem, depois de compreender, alem da estrutura, também a plasticidade interna deles, transformaos. Aquele saber é função desse agir; e é um saber ativo, porque no limite do reino das formas tem a coragem de reconhecer um caráter não definitivo. ${ }^{19}$

$\AA$ arte fundamentada em um saber, no conhecimento de verdades universais e imutáveis, sucede a arte como fazer, possibilidade técnica, capacidade de manipulação. A forma não é mais um molde preexistente, mas o resultado de um processo - criação de cantor, não teorema de mestre.

\section{Notas e Referências}

1. O Notitia Artis Musicae é conhecido também como Musica Practica, título com que foi editado por M.Gebert, Scriptores ecclesiastici de musica, St. Blasien, 1784, vol. III, p. 292; aqui utilizo a edição crítica de Hans Ulrich Michels (Corpus Scriptorum de Musica n. 17, Roma: American Institute of Musicology, 1972), que restabelece o título original.

2. M. Bloch, La sociétà féodale, trad. it. La società feudale, Torino: Einaudi, 1959, p. 127-128.

3. J. Le Goff, "Tempo della Chiesa e tempo del mercante" e "Il tempo del lavoro nella 'crisi' del sec. XIV: dal tempo medievale al tempo modemo", em: Tempo della Chiesa e tempo del mercante, Torino: Einaudi, 1986, p. 3-23 e 25-36 (originalmente em "Annales ESC", 1960, p. 417-433 e "Le Moyen Age'"', 1963, p. 597-613).

4. Tomás de Aquino, Comm. Ioann, c.11, lect.2. Dante Alighieri, Convivio, III, vi, 2-4.

5. Alexander Murray, Reason and socieiy in the Middle Age, Oxford: Clarendon Press, 1978, trad. it. Ragione e società nel Medioevo, Roma: Editori Riuniti, 1986, p. 112-114.

6. J. Le Goff, op. cit., p. 26, nota 8.

7. Guido Aretinus, Epistula ad Michaelem monachum de ignoto cantu; trad. it. em Giulio Cattin, Il Medioevo I, "Storia della Musica S.I.M.", Torino: EDT, 1981, vol. I, p. Iī, p. 194-199. Sobre o ensino da música e a organização dos coros, informaçōes importantes (relativas à Inglaterra, mas extensíveis ao resto da Europa) estão em F.L.L. Harrison, Music in Meơieval Britain, London: Routledge and Keagan Paul, 1958, p. 1-38.

8. Giulio Cattin, op. cit., p. 175-178.

9. Ver G. Sarion, Introduction to the history of science, Huntington N.Y.: Krieger, 1975, vol. I.

10. Sobre os Libros del Saber, ver G. Sarton, op. cit., vol. II, p. 168; sobre Hugues de St. Victor Ver B.

Nardi "La Reductio Artium" da Cassiodoro a S. Bonaventura" em: I Classici della pedagogia italiana: il 
Medio Evo, Cittá di Castello: Giuntine/Sansoni, 1956, p. 291-294. Cf. também, F.A. Gallo, II Medioevo II, "Storia della Musica S.I.M.", vol. II.

11. Le Goff, op. cit., p. 3 segs. Sobre a cultura universitária do século XIII Ver Le Goff, "Quale coscienza l'Università medievale ha avuto di se stessa?" e "Le Universitá e i pubblici poteri nel Medioevo e nel Rinascimento", em: op. cit., p. 153-170 e 171-192, e Os intelectuais na Idade Média, São Paulo, Brasiliense, 1988; M. de Wulf, Histoire de la philasophie médiéval, Louvain-Paris: Vorin, 1934, vol. II, p. 8-25.

12. Ver o estatuto da Faculdade de Artes de Paris, 1255, em B. Nardi, op. cit., p. 445-447. Uma Ars vetus, baseada em teorias franconianas, precede a Ars Nova de Philippe de Vitry em pelo menos um manuscrito (Paris 7378A). Quatro tratados anônimos editados por Coussemaker contêm a oposição já no título: dois De musica antiqua et nova, um Compendium artis veteris de novae, um Compendium artis mensurabilisetam veteris quam novae. (E.Coussemaker, Scriptorum de musica medii devi nova seri. Hildesheim: Oims, 1963, vol. III, p. 354-379).

13. Sarton, op. cit., vol. III, p. I, p. $652-657$ e 742-744: F. Della Seta, "Scienza e filosofia nella teoria musicale dell'Ars Nova in Francia", em: "Nuova Rivista Musicale Italiana", a.X., n. 3, 1976, p. 357-seg.; E. Werner, "The mathematical foundation of Philippe de Vitry's Ars Nova, em "Journal of American Musicological Society", IX, 1956, n.1, p. 128 segs.

14. Erwin Panofsky, Architecutre gothique et pensée scolastique, Paris: Editions de Minuit, 1970.

15. De Divisione Natura, IV, 5, cit. in De Wulf, op. cit. vol I, p. 133.

16. Tomás de Aquino, Summa Theologiac, I, Q. 85.

17. Ver de Panofsky, além da op. cit., "A história da teoria das proporções humanas como reflexo da história dos estilos", em Significado nas artes visuais, Sāo Paulo: Perspectiva, 1979, p. 122-126; e sobre o dcsenho do leẫo, E. H. Gombrich, Arte e ilusẫo, Sáo Paulo, Martins Fontes, 1986, p. 68-69.

18. Dante Alighieri, Paradiso, XVIII, 70-117.

19. E. Garin, "La crisi del pensiero medievale", em: Medioevo e Rinascimento, Bari: Laterza, 1987, p. 28.

Lorenzo Mammì é professor do Departamento de Música da Escola de Comunicações e artes da Universidade de São Paulo. 